\title{
Cryptosporidium andersoni as a novel predominant Cryptosporidium species in outpatients with diarrhea in Jiangsu Province, China
}

Yanyan Jiang ${ }^{1 \dagger}$, Jinhua Ren ${ }^{2 \dagger}$, Zhongying Yuan ${ }^{1}$, Aiqin Liư ${ }^{3}$, Hong Zhao ${ }^{2}$, Hua Liu', Lei Chu², Wei Pan', Jianping Cao ${ }^{1}$, Yijin Lin ${ }^{2 *}$ and Yujuan Shen ${ }^{1 *}$

\begin{abstract}
Background: Cryptosporidium hominis and C. parvum are usually considered to be the major pathogens responsible for human cryptosporidiosis. However, there have been few studies regarding the molecular epidemiology of Cryptosporidium in human infections in China. Here we investigated Cryptosporidium infection in patients with diarrhea, in Danyang Hospital of Jiangsu Province, China, at the genotype level.

Methods: A total of 232 stool specimens were collected from outpatients with diarrhea in Danyang Hospital of Jiangsu Province, China, from February 2012 to January 2013. Each specimen was stained from direct fecal smears and examined for Cryptosporidium using modified acid fast staining and microscopy. Moreover, genomic DNA of each fecal sample was screened for the presence of Cryptosporidium with nested PCR, which was genotyped by analyzing the DNA sequences of small subunit rRNA (SSU rRNA).

Results: The average infection rate of Cryptosporidium was 1.3\% (3/232) by microscopy and subjected to PCR amplification of the SSU rRNA gene of Cryptosporidium, with 9.91\% (23/232) being positive for Cryptosporidium with a significant peak in autumn. Based on the SSU rRNA gene, two Cryptosporidium spp. were identified, including C. andersoni $(n=21)$ and $C$. hominis $(n=2)$. Two types of $C$. andersoni, designated as $A_{370}{ }^{+}$and $A_{370}{ }^{-}$, were found in the SSU rRNA gene in our present study, which was 100\% homologous to C. andersoni infections derived from dairy calves and goats, respectively. The clinical questionnaires showed no significant difference in age, gender and frequency of diarrhea, but duration of diarrhea was shorter for $C$. andersoni than that of $C$. hominis (mean, 2 vs. 4 days; $p<0.01$.

Conclusions: $C$. andersoni is the dominant species in Danyang City of Jiangsu Province. The fact that SSU rRNA sequences of $C$. andersoni obtained from human stools exhibited 100\% homologous to those derived from dairy calves and goats supported that $C$. andersoni infection might be attributable to animal origin. The difference in the duration of diarrhea of C. andersoni and C. hominis indicated that different Cryptosporidium species might cause different clinical manifestations.
\end{abstract}

Keywords: Cryptosporidium andersoni, Diarrhea, Stool specimens, Predominant species, Prevalence

\footnotetext{
* Correspondence: jsdylyj@163.com; amyshjy12@163.com

${ }^{\dagger}$ Equal contributors

${ }^{2}$ Department of Infectious Diseases, Danyang Hospital of Jiangsu Province, Danyang 212300, People's Republic of China

${ }^{1}$ National Institute of Parasitic Diseases, Chinese Center for Disease Control and Prevention; Key Laboratory of Parasite and Vector Biology, Ministry of Health; WHO Collaborating Center for Malaria, Schistosomiasis and Filariasis, Shanghai 200025, People's Republic of China

Full list of author information is available at the end of the article
} 


\section{Background}

Cryptosporidium spp. causes significant diarrheal disease in humans and animals worldwide [1]. Increasing numbers of molecular epidemiological studies on cryptosporidiosis have provided greater understanding of the diversity of the species infecting humans. To date, 30 species and more than 70 subtypes of Cryptosporidium have been identified in diverse vertebrate hosts [2-4]. Among these, C. hominis and $C$. parvum have been shown to be the two major human pathogens by numerous studies, responsible for approximate $90 \%$ of human cryptosporidiosis [5-8]. Moreover, there appear to be geographical differences in the distribution of Cryptosporidium spp. in humans from an epidemiological viewpoint. For example, $C$. parvum is the dominant species infecting humans in the Middle-East, while $C$. hominis is considered to be responsible for the majority of human infections in developing countries, and C. parvum and C. hominis are both observed in almost equal proportions in European countries [1,9].

In China, since the first report of two human cases of cryptosporidiosis in 1987 [10], Cryptosporidium has been attracting increasing attention. Epidemiological data on human cryptosporidiosis have confirmed its common occurrence in at least 17 Chinese provinces or cities with a detection rate ranging from $1.4 \%$ to $10.4 \%$ based on morphological identification [11]. Identifying the parasite species infecting humans by molecular methods is important in determining the epidemiology of the disease and its likely transmission routes [12]. However there have been few studies conducted on the molecular epidemiology of Cryptosporidium in humans, with the exception of Shanghai [13], Henan Province [14], Hunan Province [15] and Tianjin [16]. Currently, there are only morphological data on human cryptosporidiosis in Jiangsu Province $[17,18]$. The aim of the present study was to investigate Cryptosporidium infection in patients with diarrhea using molecular tools and sequencing, in Danyang Hospital of Jiangsu Province. We then further sought to investigate the possible relationship between epidemiological data and clinical manifestations of the predominant Cryptosporidium species detected.

\section{Methods}

\section{Ethics statement}

Ethical approval for the collection and examination of human feces samples was obtained from the Ethics Committee of the Danyang Hospital of Jiangsu Province and the National Institute of Parasitic Diseases, Chinese Center for Disease Control and Prevention, China (reference no. 2012-12). The objectives, procedures and potential risks were verbally explained to all participants. Written informed consent was given to, and signed by all the study participants. Parents/guardians provided consent on behalf of all infant participants.

\section{Fecal specimen collection and examination}

Human stool specimens ( $\mathrm{n}=232$ ) were collected from Danyang Hospital of Jiangsu Province, China. All of the diarrhea patients investigated (1 month - 77 years old, medium 34.7 years old) in this study were recruited from outpatients departments during a 1-year period from February 2012 to January 2013. Patient details, including their age, gender, occurrence, duration and frequency of diarrhea, and consistency of stools, were recorded. The duration of an episode diarrhea was defined to be from the onset to attendance at the hospital. The frequency of diarrhea episodes was defined as the number of occurrences of diarrhea per day. Specimens were collected from patients with fecal excretion heavier than $200 \mathrm{mg}$ and with no less than three events of diarrhea per day. Each specimen was stained from direct fecal smears and examined for Cryptosporidium using modified acid fast staining and microscopy $[19,20]$.

\section{DNA extraction}

Sufficient samples (200 mg of each fecal sample) were collected for DNA extraction and purification using a commercially available kit, QIAamp DNA Mini Stool Kit (Qiagen, Valencia, CA). The extracted DNA samples were stored at $-30^{\circ} \mathrm{C}$ for PCR.

\section{Genotyping of Cryptosporidium}

All DNA preparations were screened for the presence of Cryptosporidium DNA by nested PCR amplification of a fragment (approximately $830 \mathrm{bp}$ ) of the SSU rRNA gene, and were identified to the species/genotype level as previously described [21,22].

Each DNA preparation was performed three times by using $1 \mu \mathrm{l}$ DNA per PCR. DNA from C. baileyi obtained from a chicken [23], provided by Prof. Longxian Zhang of Henan Agricultural University, was used as a positive control, and deionized water was used as a negative control. All nested PCR products were visualized by electrophoresis in $2 \%$ agarose gel stained with ethidium bromide before sequencing.

\section{DNA sequence analysis}

Positive secondary PCR products were subjected to twodirectional sequencing with secondary primers by the Shanghai Sunny Biotechnology Co, Ltd. (Shanghai, China). The accuracy of the sequencing data was confirmed by sequencing in both directions. Amplified sequences were blasted against sequences in the NCBI database and then deposited in GenBank (accession numbers KF826294 to KF826316) and identified by direct comparisons using the MEGA5 software of the acquired nucleotide sequences 
with each other and with reference sequences downloaded from GenBank.

\section{Statistical analysis}

Significance testing was performed using $x^{2}$ or Fishers exact test for categorical variables. Differences were considered significant at $p$ values of $<0.05$. All statistical analyses were performed using JMP software (SAS Institute, USA).

\section{Results}

Prevalence of cryptosporidiosis in patients with diarrhea in Jiangsu Province

Human stool specimens $(\mathrm{n}=232)$ were screened microscopically for the presence of Cryptosporidium oocysts. However, the average detection rate of Cryptosporidium was only $1.3 \%(3 / 232)$ by microscopy with average dimension of the Cryptosporidium oocysts of $7 \mu \mathrm{m} \times$ $5 \mu \mathrm{m}$. These specimens were also screened for the presence of Cryptosporidium by PCR (9.9\%) collected from February 2012 to January 2013 in Danyang Hospital of Jiangsu Province (Table 1). The prevalence of Cryptosporidium in different seasons was also investigated using these specimens. The mean prevalence over the four seasons ranged from $2.2 \%$ to $29.1 \%$ and showed significant variation between seasons $\left(x^{2}=9.753, p<0.05\right)$ (Table 1$)$, with a peak in autumn. The prevalence of Cryptosporidium in all age categories (with the exception of children group) ranged from $7.7 \%$ to $12.5 \%$, with no significant differences among different age groups $\left(\chi^{2}=1.666, p>0.05\right)$ (Table 2).

\section{Molecular analysis of Cryptosporidium species}

Nested PCR screening for Cryptosporidium identified 23 positive specimens. DNA sequencing of the SSU rRNA target fragments revealed the presence of two Cryptosporidium species: C. hominis $(\mathrm{n}=2)$ and $C$. andersoni $(\mathrm{n}=21)$ (Table 1). All three microscopy-positive specimens were

Table 1 The seasonal distribution of cryptosporidiosis in diarrhea outpatients in the Danyang hospital of Jiangsu province from February 2012 to January 2013

\begin{tabular}{lllll}
\hline Season & $\begin{array}{l}\text { No. } \\
\text { specimens }\end{array}$ & $\begin{array}{l}\text { No. } \\
\text { positive(\%) }\end{array}$ & C. andersoni & C. hominis \\
\cline { 4 - 5 } & 32 & $1(3.1)$ & 0 & 1 \\
Spring & 32 & $5(5.1)$ & 5 & 0 \\
Summer & 99 & $16(29.1)^{\mathrm{b}}$ & 15 & 1 \\
Wutumn & 55 & $1(2.2)$ & 1 & 0 \\
Total & 232 & $23(9.9)^{\mathrm{a}}$ & 21 & 2
\end{tabular}

NOTE. All specimens were collected from February 2012 to January 2013 (divided into four seasons) and Cryptosporidium species were detected by the SSU rRNA gene analysis.

${ }^{\mathrm{a}}$ The prevalence of Cryptosporidium infection.

${ }^{b}$ Data from autumn show a significant difference compared with those of other seasons $\left(x^{2}=9.753, p<0.05\right)$. further confirmed to be $C$. andersoni by PCR and sequencing of the SSU rRNA gene. In addition, two distinct $C$. andersoni sequences were classified at the SSU rRNA locus. Of the 21 SSU rRNA $C$. andersoni sequences obtained (771 bp in length), 12 sequences were assigned as $\mathrm{A}_{370}{ }^{-}$type (KF826294, KF826295, KF826296, KF826298, KF826299, KF826303, KF826304, KF826305, KF826307, KF826310, KF826311, KF826313) and nine sequences as $\mathrm{A}_{370}{ }^{+}$type (KF826297, KF826300, KF826301, KF826302, KF826306, KF826308, KF826309, KF826312, KF826314), based on the absence or presence, respectively, of an A at position 370 of the nucleotide sequence. $\mathrm{A}_{370}{ }^{-}$type exhibited $100 \%$ homology with the $C$. andersoni isolated from dairy calves (JX515549), while $\mathrm{A}_{370}{ }^{+}$type exhibited $100 \%$ homology with the $C$. andersoni isolated from a goat (EU926593).

\section{Characteristics associated with C. andersoni infection}

According to Cryptosporidium infection among these age groups, $C$. hominis infection was found in two specimens from the adult group and elderly group, respectively, with an overall detection rate of $8.7 \%$ (Table 2). In contrast, C. andersoni infection was more commonly found in diarrheal patients, with the exception of children (Table 2). There were no significant differences in C. andersoni detection rates between the different age groups $\left(x^{2}=1.82, p>0.05\right)$. However, according to our data, the detection rate of $C$. andersoni infection was $33.3 \%$ in infants and $38.1 \%$ in elderly patients. Further analysis of the results showed no significant difference in the overall number of Cryptosporidium-positive specimens between the genders $\left(x^{2}=3.74, p>0.05\right)$; however the gender distribution of $C$. andersoni infection was four (19.05\%) female and 17 (81.0\%) male patients, compared with one female (KF826315) and one male patient (KF826316) for C. hominis (Table 2).

Analysis of associated information reported revealed that the outpatients with $C$. andersoni attended the hospital after a shorter duration of diarrhea compared to those with $C$. hominis infection (mean, 2 days and 4 days, respectively; $p<0.01$ ). Although there was no significant difference in the frequency of diarrhea episodes between these two species, we noticed a tendency for $C$. andersoni to result in more serious diarrhea, with a mean frequency of five times per day (Table 2).

\section{Discussion}

Knowledge of Cryptosporidium species is essential to the management of cryptosporidiosis and reduction in the risks of continued disease prevalence. In this study, the prevalence of Cryptosporidium spp. infection in our study was $1.3 \%$ according to microcopy versus $9.9 \%$ by $\mathrm{PCR}$, and all three microscopy-positive specimens were confirmed as being C. andersoni by both PCR and 
Table 2 Feature distribution of Cryptosporidium spp. and subtype in Danyang hospital of Jiangsu province from February 2012 to January 2013

\begin{tabular}{|c|c|c|c|c|}
\hline Feature & No. samples & No. positive(\%) & C. andersoni(\%) & C. hominis \\
\hline Cases & 232 & $23(9.9)$ & $21(91.3)$ & $2(8.7)$ \\
\hline \multicolumn{5}{|l|}{ Age category $(y r)^{a}$} \\
\hline Infants ( $<5$ years), $\mathrm{n}(\%)$ & 66 & $7(10.7)$ & $7(33.3)$ & 0 \\
\hline Children (5-12 years), n (\%) & 6 & $0(0.0)$ & 0 & 0 \\
\hline Youths (13-19 years), n (\%) & 10 & $1(10.0)$ & $1(4.8)$ & 0 \\
\hline Adults (20-49), n (\%) & 78 & $6(7.7)$ & $5(23.8)$ & 1 \\
\hline Elderly (50 years up), n (\%) & 72 & $9(12.5)$ & $8(38.1)$ & 1 \\
\hline \multicolumn{5}{|l|}{ Gender } \\
\hline Female & 94 & $5(5.3)$ & $4(19.1)$ & $1(50.0 \%)$ \\
\hline Male & 138 & $18(13.0)$ & $17(81.0)$ & $1(50.0 \%)$ \\
\hline \multicolumn{5}{|l|}{ Infection episode } \\
\hline Duration of diarrhea, days & 4 & 3 & $2^{\mathrm{b}}$ & 4 \\
\hline Frequency of diarrhea, times & 6 & 5 & 5 & 3.5 \\
\hline
\end{tabular}

NOTE. All specimens were detected by the SSU rRNA gene analysis of Cryptosporidium species. ${ }^{\mathrm{a}}$ There was no significant difference in the prevalence of

Cryptosporidium among all age categories $\left(x^{2}=1.666, p>0.05\right)$. ${ }^{b}$ Statistically significant at $p<0.01$ with $C$. andersoni infection $(n=21)$ vs. $C$. hominis infection $(n=2)$.

sequencing of SSU rRNA gene. The result might be related to the fact that $C$. andersoni are larger than those of $C$. hominis. Meanwhile, no difference was observed morphologically between the dimensions of $C$. andersoni oocysts from humans in this study and those from animals reported previously [24]. Our molecular data was more sensitive and accurate than morphologic data, which was within the reported the range of $1.4 \%-10.4 \%$ of all patients with diarrhea for infections attributed to Cryptosporidium in China [10,15]. However, our data for different age groups showed a detection rate of $12.5 \%$ in elderly patients, which was higher than that reported for elderly patients in Changchun (8.6\%) [25]. This difference may be attributed to different detection methods in the same age group because PCR and microscopy detection were used in this study, while serological detection was used in the Changchun study. Our study indicates that molecular methods of detection have the advantage of increased sensitivity compared with conventional and immunological assays for detecting oocysts in feces. We also found an infection rate of $10.6 \%$ in infants in our study, which was higher than that of any pediatric hospital $(0.4 \%-2.8 \%)$ in Shanghai [13]. These differences in prevalence may in part be related to differences in experimental design, specimen sources, and whether or not the patients were staying in hospital. In addition, our data also confirmed that seasonal variation can affect the prevalence of Cryptosporidium, with a peak in autumn [26,27].

Although C. hominis and C. parvum account for more than $90 \%$ of human cases of cryptosporidiosis [2], other species that have also been associated with human disease globally include C. meleagridis, C. cuniculus, C. ubiquitum, C. felis, C. canis and C. andersoni as well as C. muris
[5,28-32]. There is considerable regional diversity in the distribution of Cryptosporidium species in China; $C$. hominis has been reported to be the predominant cause of infection in Eastern China [13,16,33], while C. par$v u m$ is the predominant species in Hunan Province [15]. However, the results of our study clearly showed that $C$. andersoni has become a novel predominant species (21 C. andersoni infections out of 23 cases) among outpatients with diarrhea in the geographical area investigated.

As a species with narrow host specificity [34], $C$. andersoni was usually detected primarily in domestic cattle [24]. Only a few cases have been published regarding human C. andersoni infections in France [35], Malawi [36], Iran [37], England [5] and Australia [38]. However, a recent study by our group [39] reported 34 C. andersoni in 252 human patients with diarrhea in Shanghai. And in this study, we also found 21 cases of C. andersoni infection. It is unclear why so many cases of human cryptosporidiosis are caused by $C$. andersoni in the investigated areas. The true source of $C$. andersoni infection needs to be elucidated by subtyping $C$. andersoni isolates from humans and animals in the future, as well as analyses of its transmission dynamics. Furthermore, these sequences of the 21 cases of $C$. andersoni were divided into two types, which 12 sequences belonging to $\mathrm{A}_{370}{ }^{-}$type were identical to an isolate from a dairy calf (JX515549), while the others of 9 sequences belonging to $\mathrm{A}_{370}{ }^{+}$type were identical to an isolate from a goat (EU926593). This suggests that $C$. andersoni has become the new major Cryptosporidium species to infect humans, and its zoonotic transmission may be from animals to humans either directly or indirectly. We have 
already assessed further genetic sources of human $C$. andersoni infections using multilocus sequence typing (MLST), which has also been used for exploring genetic sources of $C$. andersoni infection in zoonotic samples $[34,40]$ and confirmed at least two sites from cattle to be consistent with our current data (data not shown).

C. andersoni is also one of the main Cryptosporidium species found in contaminated water such as the Potomac River in the United States [41], the Huangpu River in Shanghai [42], and in the urban wastewater plants in Harbin [43]. It is reasonable to suggest that $C$. andersoni infected humans could shed C. andersoni oocysts into urban wastewater, thus further contaminating water supplies and resulting in anthroponotic transmission of $C$. andersoni. It is therefore essential to conduct further investigation into the transmission dynamics of Cryptosporidium between dairy calves, humans and water resources in different geographic locations.

\section{Conclusion}

In conclusion, the present findings, including distribution and genetic characterization of Cryptosporidium at the molecular level in patients with diarrhea, may be representative of the other molecular characteristics of human cryptosporidiosis. Whether or not the $C$. andersoni identified in patients with diarrhea in this study represented a natural infection needs to be confirmed with more systematic characterization of cryptosporidiosis and experimental infection studies.

\section{Abbreviations \\ C. hominis: Cryptosporidium hominis; C. parvum: Cryptosporidium parvum; C. andersoni: Cryptosporidium andersoni; SSU rRNA: Small subunit rRNA.}

\section{Competing interests}

The authors declare that they and their institutions have no financial or personal relationships with other people or organizations that could inappropriately influence (bias) their actions.

\section{Authors' contributions}

YS, JC and YL conceived and designed the experiments; YJ, ZY, HZ, HL, LC and WP performed the experiments; YJ, JR and YS analyzed the data, statistical analysis and writing up the manuscript; JC, AL and YS critically revised the manuscript. All authors read and approved the final version of the manuscript.

\section{Acknowledgments}

This work was supported by the Chinese Special Program for Scientific Research of Public Health (No. 201302004, to Y.S.), the Shanghai Public Health Outstanding Academic Leader (No. GWDTR201214, to Y.S.) and the National S \& T Major Program (No. 2012ZX10004-201, to J.C.).

\section{Author details}

'National Institute of Parasitic Diseases, Chinese Center for Disease Control and Prevention; Key Laboratory of Parasite and Vector Biology, Ministry of Health; WHO Collaborating Center for Malaria, Schistosomiasis and Filariasis, Shanghai 200025, People's Republic of China. ${ }^{2}$ Department of Infectious Diseases, Danyang Hospital of Jiangsu Province, Danyang 212300, People's Republic of China. ${ }^{3}$ Department of Parasitology, Harbin Medical University, Harbin 150081, People's Republic of China.

Received: 16 June 2014 Accepted: 10 October 2014

Published online: 25 October 2014

\section{References}

1. Desai NT, Sarkar R, Kang G: Cryptosporidiosis: an under-recognized public health problem. Trop Parasitol 2012, 2(2):91-98.

2. Xiao L: Molecular epidemiology of cryptosporidiosis: an update. Exp Parasitol 2010, 124(1):80-89.

3. Elwin K, Hadfield SJ, Robinson G, Crouch ND, Chalmers RM: Cryptosporidium viatorum n. sp. (Apicomplexa: Cryptosporidiidae) among travellers returning to Great Britain from the Indian subcontinent, 2007-2011. Int J Parasitol 2012, 42(7):675-682.

4. Slapeta J: Cryptosporidiosis and Cryptosporidium species in animals and humans: a thirty colour rainbow? Int J Parasitol 2013, 43(12-13):957-970.

5. Leoni F, Amar C, Nichols G, Pedraza-Diaz S, McLauchlin J: Genetic analysis of Cryptosporidium from 2414 humans with diarrhoea in England between 1985 and 2000. J Med Microbio/ 2006, 55(Pt 6):703-707.

6. Elwin K, Hadfield SJ, Robinson G, Chalmers RM: The epidemiology of sporadic human infections with unusual cryptosporidia detected during routine typing in England and Wales, 2000-2008. Epidemiol Infect 2012 140(4):673-683.

7. Kvac M, Kvetonova D, Sak B, Ditrich O: Cryptosporidium pig genotype II in immunocompetent man. Emerg Infect Dis 2009, 15(6):982-983.

8. Zhu H, Zhao J, Wang R, Zhang L: Molecular identification of a rare subtype of Cryptosporidium hominis in infants in China. PLoS One 2012, 7(8):e43682.

9. Ajjampur SS, Sarkar R, Sankaran P, Kannan A, Menon VK, Muliyil J, Ward H, Kang G: Symptomatic and asymptomatic Cryptosporidium infections in children in a semi-urban slum community in southern India. Am J Trop Med Hyg 2010, 83(5):1110-1115.

10. Han F, Tan WX, Zhou XL: Two case reports of cryptosporidiosis in Nanjing. Jiangsu Med J 1987, 13(12):692.

11. Lv S, Tian LG, Liu Q, Qian MB, Fu Q, Steinmann P, Chen JX, Yang GJ, Yang K, Zhou XN: Water-related parasitic diseases in China. Int J Environ Res Public health 2013, 10(5):1977-2016.

12. Xiao L, Fayer R, Ryan U, Upton SJ: Response to the newly proposed species Cryptosporidium pestis. Trends Parasitol 2007, 23(2):41-42.

13. Feng Y, Wang L, Duan L, Gomez-Puerta LA, Zhang L, Zhao X, Hu J, Zhang $\mathrm{N}$, Xiao L: Extended outbreak of cryptosporidiosis in a pediatric hospital, China. Emerg Infect Dis 2012, 18(2):312-314.

14. Wang L, Zhang H, Zhao X, Zhang L, Zhang G, Guo M, Liu L, Feng Y, Xiao L: Zoonotic Cryptosporidium species and Enterocytozoon bieneusi genotypes in HIV-positive patients on antiretroviral therapy. J Clin Microbiol 2013, 51(2):557-563.

15. Yu Z, Li F, Zeng Z, Huang Z, Fan Z, Jin Y, Luo W, Xiang X, Deng Q: Prevalence and clinical significance of Cryptosporidium infection in patients with hepatitis $B$ virus-associated acute-on-chronic liver failure. Int J Infect Dis 2011, 15(12):e845-e848.

16. Peng MM, Matos O, Gatei W, Das P, Stantic-Pavlinic M, Bern C, Sulaiman IM, Glaberman S, Lal AA, Xiao L: A comparison of Cryptosporidium subgenotypes from several geographic regions. J Eukaryot Microbiol 2001, Suppl:28S-31S.

17. Chen YG, Yao FB, Li HS, Shi WS, Dai MX, Lu M: Cryptosporidium infection and diarrhea in rural and urban areas of Jiangsu, People's Republic of China. J Clin Microbiol 1992, 30(2):492-494.

18. Chen YG, Yao FB, Li HS, Shi WS, Dai MX, Lu M: [Epidemiological studies on human cryptosporidiosis in rural and urban areas of Jiangsu]. Chin J Parasitol Parasitic Dis 1993, 11(3):207-210.

19. Zhang W, Yang F, Liu A, Wang R, Zhang L, Shen Y, Cao J, Ling H: Prevalence and genetic characterizations of Cryptosporidium spp. in pre-weaned and post-weaned piglets in Heilongjiang Province, China. PLoS One 2013, 8(7):e67564.

20. Ma P, Soave R: Three-step stool examination for cryptosporidiosis in 10 homosexual men with protracted watery diarrhea. J Infect Dis 1983, 147(5):824-828.

21. Yin J, Shen Y, Yuan Z, Lu W, Xu Y, Cao J: Prevalence of the Cryptosporidium pig genotype II in pigs from the Yangtze River Delta, China. PLoS One 2011, 6(6):e20738.

22. Xiao L, Bern C, Limor J, Sulaiman I, Roberts J, Checkley W, Cabrera L, Gilman $\mathrm{RH}$, Lal AA: Identification of 5 types of Cryptosporidium parasites in children in Lima, Peru. J Infect Dis 2001, 183(3):492-497.

23. Wang $R$, Jian F, Sun $Y$, Hu Q, Zhu J, Wang F, Ning C, Zhang L, Xiao L: Large-scale survey of Cryptosporidium spp. in chickens and Pekin ducks (Anas platyrhynchos) in Henan, China: prevalence and molecular characterization. Avian Pathol 2010, 39(6):447-451. 
24. Lindsay DS, Upton SJ, Owens DS, Morgan UM, Mead JR, Blagburn BL: Cryptosporidium andersoni n. sp. (Apicomplexa: Cryptosporiidae) from cattle, Bos taurus. J Eukaryot Microbiol 2000, 47(1):91-95.

25. Song JP, Zhao JX, Gao H, Liu Y, Yue HX, Zhang J, Su Y, Yin JG: [Serological detection of Cryptosporidium spp. infection in outpatients in Changchun]. Chin J Parasitol Parasitic Dis 2011, 29(3):239-241.

26. Leitch GJ, He Q: Cryptosporidiosis-an overview. J Biomed Res 2012, 25(1):1-16.

27. Chalmers RM, Elwin K, Hadfield SJ, Robinson G: Sporadic human cryptosporidiosis caused by Cryptosporidium cuniculus, United Kingdom, 2007-2008. Emerg Infect Dis 2011, 17(3):536-538.

28. Chalmers RM, Robinson G, Elwin K, Hadfield SJ, Xiao L, Ryan U, Modha D, Mallaghan C: Cryptosporidium sp. rabbit genotype, a newly identified human pathogen. Emerg Infect Dis 2009, 15(5):829-830.

29. Gatei W, Ashford RW, Beeching NJ, Kamwati SK, Greensill J, Hart CA: Cryptosporidium muris infection in an HIV-infected adult, Kenya. Emerg Infect Dis 2002, 8(2):204-206.

30. Gatei W, Suputtamongkol Y, Waywa D, Ashford RW, Bailey JW, Greensill J, Beeching NJ, Hart CA: Zoonotic species of Cryptosporidium are as prevalent as the anthroponotic in HIV-infected patients in Thailand. Ann Trop Med Parasitol 2002, 96(8):797-802.

31. Akiyoshi DE, Dilo J, Pearson C, Chapman S, Tumwine J, Tzipori S: Characterization of Cryptosporidium meleagridis of human origin passaged through different host species. Infect Immun 2003, 71(4):1828-1832.

32. Palmer CJ, Xiao L, Terashima A, Guerra H, Gotuzzo E, Saldias G, Bonilla JA Zhou L, Lindquist A, Upton SJ: Cryptosporidium muris, a rodent pathogen, recovered from a human in Peru. Emerg Infect Dis 2003, 9(9):1174-1176.

33. Wang $R$, Zhang $X$, Zhu H, Zhang L, Feng Y, Jian F, Ning C, Qi M, Zhou Y, Fu K, Wang Y, Sun Y, Wang Q, Xiao L: Genetic characterizations of Cryptosporidium spp. and Giardia duodenalis in humans in Henan, China. Exp Parasitol 2011, 127(1):42-45.

34. Feng Y, Yang W, Ryan U, Zhang L, Kvac M, Koudela B, Modry D, Li N, Fayer R, Xiao $L$ : Development of a multilocus sequence tool for typing Cryptosporidium muris and Cryptosporidium andersoni. J Clin Microbiol 2011, 49(1):34-41.

35. Guyot K, Follet-Dumoulin A, Lelievre E, Sarfati C, Rabodonirina M, Nevez G, Cailliez JC, Camus D, Dei-Cas E: Molecular characterization of Cryptosporidium isolates obtained from humans in France. J Clin Microbiol 2001, 39(10):3472-3480.

36. Morse TD, Nichols RA, Grimason AM, Campbell BM, Tembo KC, Smith HV: Incidence of cryptosporidiosis species in paediatric patients in Malawi. Epidemiol Infect 2007, 135(8):1307-1315.

37. Agholi M, Hatam GR, Motazedian MH: HIV/AIDS-associated opportunistic protozoal diarrhea. AIDS Res Hum Retroviruses 2013, 29(1):35-41.

38. Waldron LS, Dimeski B, Beggs PJ, Ferrari BC, Power ML: Molecular epidemiology, spatiotemporal analysis, and ecology of sporadic human cryptosporidiosis in Australia. Appl Environ Microbiol 2011, 77(21):7757-7765.

39. Liu H, Shen Y, Yin J, Yuan Z, Jiang Y, Xu Y, Pan W, Hu Y, Cao J: Prevalence and genetic characterization of Cryptosporidium, Enterocytozoon. Giardia and Cyclospora in diarrheal outpatients in China. BMC Infect Dis 2014, 14:25.

40. Wang R, Jian F, Zhang L, Ning C, Liu A, Zhao J, Feng Y, Qi M, Wang H, Lv C, Zhao G, Xiao L: Multilocus sequence subtyping and genetic structure of Cryptosporidium muris and Cryptosporidium andersoni. PLoS One 2012, 7(8):e43782.

41. Yang W, Chen P, Villegas EN, Landy RB, Kanetsky C, Cama V, Dearen T, Schultz CL, Orndorff KG, Prelewicz GJ, Brown MH, Young KR, Xiao L: Cryptosporidium source tracking in the Potomac River watershed. Appl Environ Microbiol 2008, 74(21):6495-6504.

42. Feng Y, Zhao X, Chen J, Jin W, Zhou X, Li N, Wang L, Xiao L: Occurrence, source, and human infection potential of Cryptosporidium and Giardia spp. in source and tap water in shanghai, china. Appl Environ Microbiol 2011, 77(11):3609-3616.

43. Liu A, Ji H, Wang E, Liu J, Xiao L, Shen Y, Li Y, Zhang W, Ling H: Molecular identification and distribution of Cryptosporidium and Giardia duodenalis in raw urban wastewater in Harbin, China. Parasitol Res 2011, 109(3):913-918.

doi:10.1186/s12879-014-0555-7

Cite this article as: Jiang et al:: Cryptosporidium andersoni as a novel predominant Cryptosporidium species in outpatients with diarrhea in Jiangsu Province, China. BMC Infectious Diseases 2014 14:555.

\section{Submit your next manuscript to BioMed Central and take full advantage of:}

- Convenient online submission

- Thorough peer review

- No space constraints or color figure charges

- Immediate publication on acceptance

- Inclusion in PubMed, CAS, Scopus and Google Scholar

- Research which is freely available for redistribution 